\title{
Idiopathic urinary bladder rupture in two mares
}

\section{Ruptura idiopática de bexiga urinária em duas éguas}

\author{
Ronaldo Avella Lavado ${ }^{1}$ (D); Luis Claudio Lopes Correia da Silva ${ }^{1}$; Aline Magalhães Ambrósio후 \\ Paulo Ari Tietböhl Leiria ${ }^{1,2}$; Carla Bargi Belli ${ }^{1}$ \\ ${ }^{1}$ Universidade de São Paulo, Faculdade de Medicina Veterinária e Zootecnia, São Paulo - SP, Brazil \\ ${ }^{2}$ Hospital Veterinário Equivet, Indaiatuba - SP, Brazil
}

\begin{abstract}
Urinary bladder rupture is rarely reported in adult horses and is usually associated with parturition, history of trauma or urethral obstruction. This paper reports two cases in mares free of these predisposing factors, diagnosed through clinical manifestations, abdominal ultrasound and abdominocentesis, corrected by cystorrhaphy through laparotomy. While recovery was satisfactory in one case, the other case had complications in celiorraphy such as development of incisional hernia, small colon eventration and intestinal adherences, opting by the euthanasia of the animal. These reports are important because of the rarity with which they occur in adult mares. The different prognoses may be related to the severity of each case, according to the location and extension of the wound, which directly or indirectly influence the technique and recovery of the animals.
\end{abstract}

Keywords: Adult mare. Cystorrhexis. Uroperitoneum. Laparotomy. Complications.

\section{RESUMO}

A ruptura de bexiga urinária é raramente relatada em equinos adultos, sendo normalmente associada ao parto, antecedentes de trauma ou obstrução de uretra. Este trabalho relata dois casos em éguas livres destes fatores predisponentes, diagnosticados através de manifestações clínicas, ultrassonografia abdominal e abdominocentese, corrigidos por cistorrafia através de laparotomia. Em um dos casos a recuperação ocorreu satisfatoriamente, porém no outro houve complicações na celiorrafia como desenvolvimento de hérnia incisional, eventração de cólon menor e posterior desenvolvimento de aderências intestinais, optando-se pela eutanásia do animal. Estes relatos são importantes pela raridade com que ocorrem em éguas adultas. Os diferentes prognósticos podem estar relacionados à gravidade de cada caso, de acordo com o local e extensão da ferida, que direta ou indiretamente influenciam na técnica empregada e recuperação dos animais.

Palavras-chave: Égua adulta. Ruptura de bexiga. Uroperitônio. Laparotomia. Complicações.

Correspondence to:

Ronaldo Avella Lavado

Universidade de São Paulo, Faculdade de Medicina Veterinária

e Zootecnia

Av. Prof. Dr. Orlando Marques de Paiva, 87, Cidade

Universitária

CEP: 05508 270, São Paulo - SP, Brazil

e-mail: ronaldo.avella@usp.br

Received: July 29, 2019

Approved: December 11, 2019
How to cite: Lavado RA, Silva LCLC, Ambrósio AM, Leiria PAT, Belli CB. Idiopathic urinary bladder rupture in two mares. Braz J Vet Res Anim Sci. 2019;56(4):e160441. https://doi.org/10.11606/issn.1678-4456.bjvras.2019.160441

Urinary bladder rupture (cystorrhexis) is the main cause of uroperitoneum in horses and occurs most commonly in male neonatal foals (Lillich et al., 2006) and, in adult horses, occurs secondarily to parturition, dystocia, trauma or ureteral obstruction due to the presence of uroliths, 
hematoma or neoplasia (Walesby et al., 2002; May et al., 2008; Tuohy et al., 2009). There was no case report found in literature of urinary bladder rupture in mares free from the above mentioned most common predisposing factors. Uroperitoneum can be diagnosed both in foals and adults based on clinical signs, such as depression, loss of appetite, progressive abdominal distension, dehydration, colic and pollakiuria, combined with abdominocentesis, blood analysis, cystoscopy and transcutaneous and transrectal ultrasonography (Rijkenhuizen et al., 2008; Tuohy et al., 2009; Jenei, 2012). The size and location of the rupture and the surgeon's preferences are determinant factors to decide the management of cystorrhexis (Tuohy et al., 2009). Cystorrhaphy can be performed through laparotomy, urethral sphincterotomy and eversion of the bladder into the vagina in mares, laparoscopy, or even conservative procedures when there is a rupture smaller than $5 \mathrm{~cm}$ (Hendrickson \& Lee, 2012). The aim of this study was to describe two cases of urinary bladder rupture in mares, which did not foal and were not under other common predisposing factors previous to this clinical condition, attended in a reference hospital.

Animal A was a 13-year-old Brasileiro de Hipismo (Brazilian Sport Horse) overweight mare, $518 \mathrm{~kg}$ of body weight, kept in a semi-stabled regime and during estrus. At 6 p.m. of the afternoon before the attendance, when clinical alterations began to appear, the responsible for the mare referred fever, oliguria with higher urinary concentration, vulvar bloody secretion, preserved appetite and denied trauma. On admission, the mare's abdomen was very tense and sensitive, she tried to stay in an antalgic position, with forelimbs displaced caudally, and kyphosis (Figure 1A). Presented discomfort at the palpation and movement, heart rate of $60 \mathrm{bpm}$, respiratory rate of $24 \mathrm{bpm}$, body temperature of $38.5^{\circ} \mathrm{C}, 3$ seconds of capillary refill time, pink eye and buccal mucosa and a hematocrit of $44 \%$. Through inspection, there was no evidence of scars, lacerations or hematomas in her abdomen that could suggest a trauma, and the animal did not present neurological alterations. The urinary bladder rupture was diagnosed through observation of clinical signs and paracentesis, presenting a yellow bloody liquid with a urine-like smell (Figure 1B), whose lactate concentration was $3.0 \mathrm{mmol} / \mathrm{L}$ while the serum concentration was $3.1 \mathrm{mmol} / \mathrm{L}$, and creatinine concentration was higher than that of serum. In an emergency, cystorrhaphy is indicated with no further exams.

Immediately before the surgery, mare's hematocrit was $36 \%$ and did not present hyperkalemia $(3.3 \mathrm{mmol} / \mathrm{L})$, a condition commonly found in foals with uroperitoneum (Walesby et al., 2002). During the surgery, the mare was intubated and positioned in dorsal recumbence under general anesthesia with isoflurane. A skin and subcutaneous incision of $10 \mathrm{~cm}$ was made in the alba line, in the udder region. A large amount of hemorrhagic peritoneal liquid was

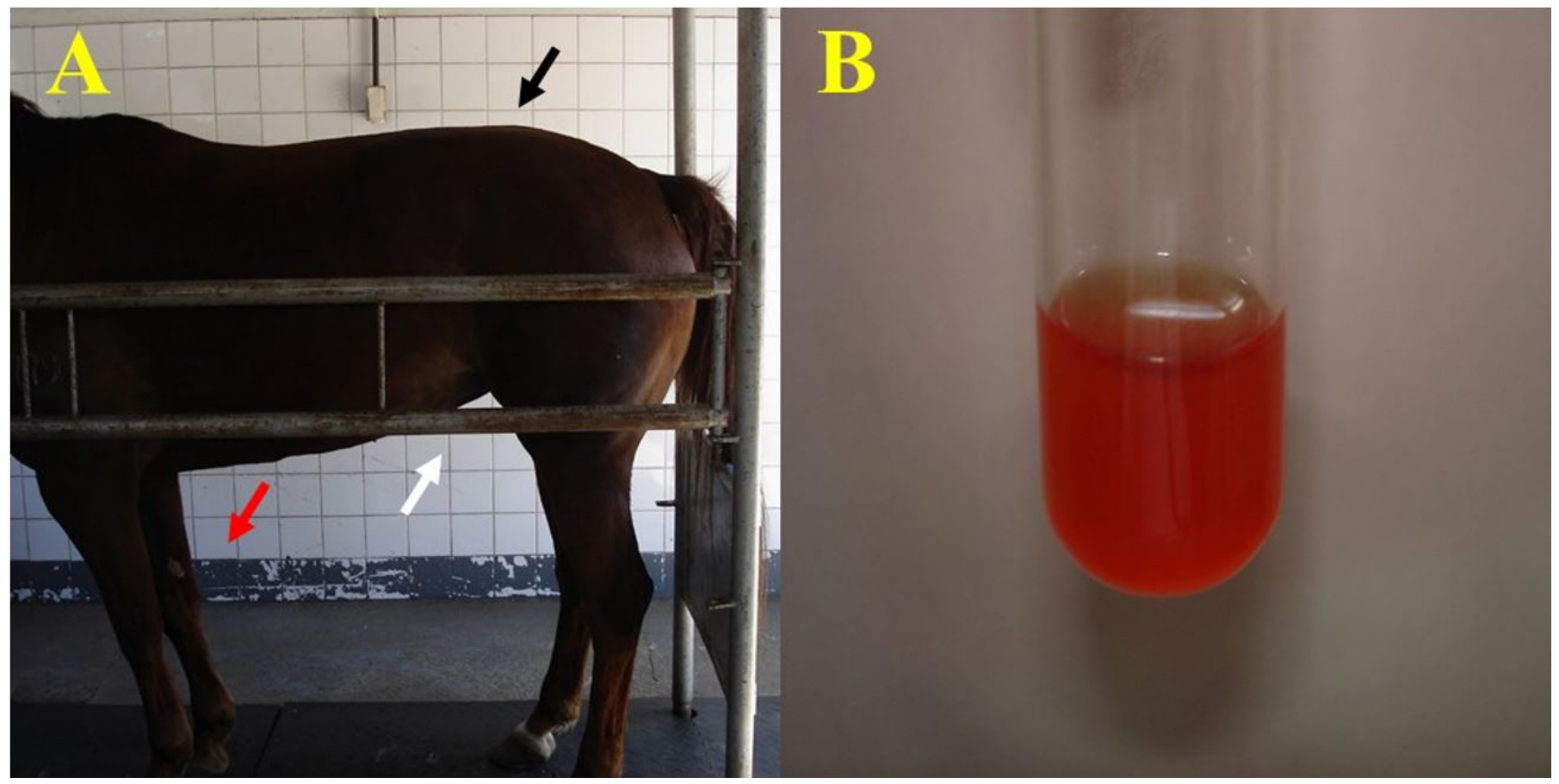

Figure 1 -Clinical findings in a mare with urinary bladder rupture: A) Contracted abdomen (white arrow), antalgic posture due to abdominal pain: forelimbs displaced caudally (red arrow) and kyphosis (black arrow); B) Aspect of a yellow bloody peritoneal liquid collected through paracentesis. 
observed in the cavity with presence of urine, posteriorly removed using a surgical suction pump. Thus, a condition was confirmed of aseptic peritonitis due to uroperitoneum, evidencing an inflamed and hyperemic peritoneum, with no viscera adherences. The bladder, whose serosa and mucosa were also inflamed, and its rupture point of approximately $7 \mathrm{~cm}$ long in the dorsal region were easily found, presenting necrotic borders, removed using a delicate scissor. There was not found uroliths and urine sediments inside the bladder or in the cavity. During the cystorrhaphy, one layer of simple continuous pattern, in the mucosa, and one layer of Cushing pattern, in the seromuscular, were performed with Caprofy ${ }^{\circledR} n^{\circ} 2-0$ suture thread. The abdominal cavity was washed with 5 liters of lactated Ringer's solution and then a solution of 1 liter of lactated Ringer's solution with $50 \mathrm{~mL}$ of dimethyl sulfoxide and $5 \mathrm{~mL}$ of heparin was poured. The muscular layer of abdomen was sutured with Prolene ${ }^{\circledR} n^{\circ} 2$ suture thread using Sultan and interrupted simple patterns intercalated, the subcutaneous layer with Vicryl ${ }^{\circledR} n^{\circ} 2-0$ using continuous Wolff pattern and the skin with nylon 2-0 using Wolff interrupted pattern. After surgery, the mare received a intravenous injection of flunixin meglumine $1.1 \mathrm{mg} / \mathrm{kg}$ btw SID and dimethyl sulfoxide $150 \mathrm{~mL} \mathrm{10 \%} \mathrm{SID} \mathrm{for} 5$ days, gentamicin $6.6 \mathrm{mg} / \mathrm{kg}$ btw SID for 7 days, diluted calcium $100 \mathrm{~mL}$ BID for 3 days and, via subcutaneous administration, heparin $5 \mathrm{~mL}$ BID for 8 days. The wound was cleaned using Dakin solution BID between days 2 and 14 after surgery, when the stitches were removed. The mare recovered satisfactorily, with resumption of normal urination after 3 days, and she was discharged from hospital 14 days after the procedure with no complications in the following months.

Animal B was an 11-year-old Brasileiro de Hipismo (Brazilian Sport Horse) mare, a practitioner of show jumping, weighing $488 \mathrm{~kg}$, kept in a stabled regime. On the day before the attendance, difficulty and reluctance to exercise, anuria, bleeding in the vulvar region were reported, as well as Flehmen response, kyphosis, absence of fever, and she was treated at the property with flunixin meglumine, fluid therapy and the nasogastric intubation were unproductive. On admission, the mare presented vaginitis, large amount of limpid urine collected through ureteral catheterization and at the per rectum examination, which was painful, the bladder wall was thickened. During initial examination, the animal presented a heart rate of $40 \mathrm{bpm}$, respiratory rate of $32 \mathrm{bpm}$, body temperature of $38^{\circ} \mathrm{C}, 2-3$ seconds of capillary refill time, pink eye and buccal mucosa and a hematocrit of $34 \%$. As in animal A, there was no alteration in her abdominal tegument and no neurological alterations. The diagnostic was possible through the observation of clinical signs, such as abdominal pain, paracentesis producing a hemorrhagic yellow fluid and with a urine-like smell. A transcutaneous ultrasonography evidenced the presence of an anechoic free fluid in the abdominal cavity and, through cystoscopy, a swollen and hyperemic bladder mucosa, as well as the rupture point with presence of fibrin, were observed.

The patient was immediately prepared to surgery in the same way as animal A and also did not present hyperkalemia (3.6 $\mathrm{mmol} / \mathrm{L}$ ). As the abdominal cavity was opened through a skin incision of approximately $20 \mathrm{~cm}$ long in the alba line, caudal to the umbilical scar, a larger amount of free liquid was observed, compared to animal A. The abdominal condition was very similar to that of animal A, with hyperemic peritoneum and viscera, free from adherences, with no uroliths found. A rupture of approximately $15 \mathrm{~cm}$ was observed along bladder's ventral area, with fibrin in all its extension (Figure 2A). After partial exteriorization, cystorrhaphy was performed using a Vicryl ${ }^{\circledR} n^{\circ} 0$ suture thread to make one layer of simple continuous pattern in the mucosa and two layers of Cushing pattern in the seromuscular of the bladder (Figure 2B). At the end of the suture, the bladder was filled with lactated Ringer's solution (Figure 2B) in order to evaluate a possible drain point, was drained out and then positioned on its anatomical position. The muscular layer of abdomen was sutured with Prolene ${ }^{\circledR}$ no. 2 suture thread using Sultan and interrupted simple patterns intercalated, the subcutaneous with Vicryl ${ }^{\circledR}$ no. 0 using Cushing pattern and the skin, with nylon no. 2-0 using simple interrupted pattern. The surgery lasted 6 hours, the mare was maintained with hyponatraemia (133 $\mathrm{mmol} / \mathrm{L}$ ) and hypercapnia $(41-57 \mathrm{mmHg})$ during the procedure.

After surgery, the patient received intravenous enrofloxacin $5 \mathrm{mg} / \mathrm{kg}$ btw SID, ceftiofur $5 \mathrm{mg} / \mathrm{kg}$ btw SID and flunixin meglumine $1.1 \mathrm{mg} / \mathrm{kg}$ btw SID for 5 days, dimethyl sulfoxide $10 \% 150 \mathrm{~mL}$ SID for 3 days and the wound was cleaned using Dakin solution BID between days 3 and 8 after surgery. Laboratory findings were consistent with what was expected after surgery, presenting anemia $\left(6.3 \times 10^{6} / \mathrm{mm}^{3}\right)$, uremia $(63.7 \mathrm{mg} / \mathrm{dL})$, increase of serum AST (750.4 U/L) and hiperbillirubinemia (5.37 mg/dL). Eight days after the surgical procedure, the animal did not show any general dysfunction and was discharged from the hospital. One month later, the mare returned to the hospital presenting an increased amount of floating liquid in the ventral region of the abdomen and, at the 


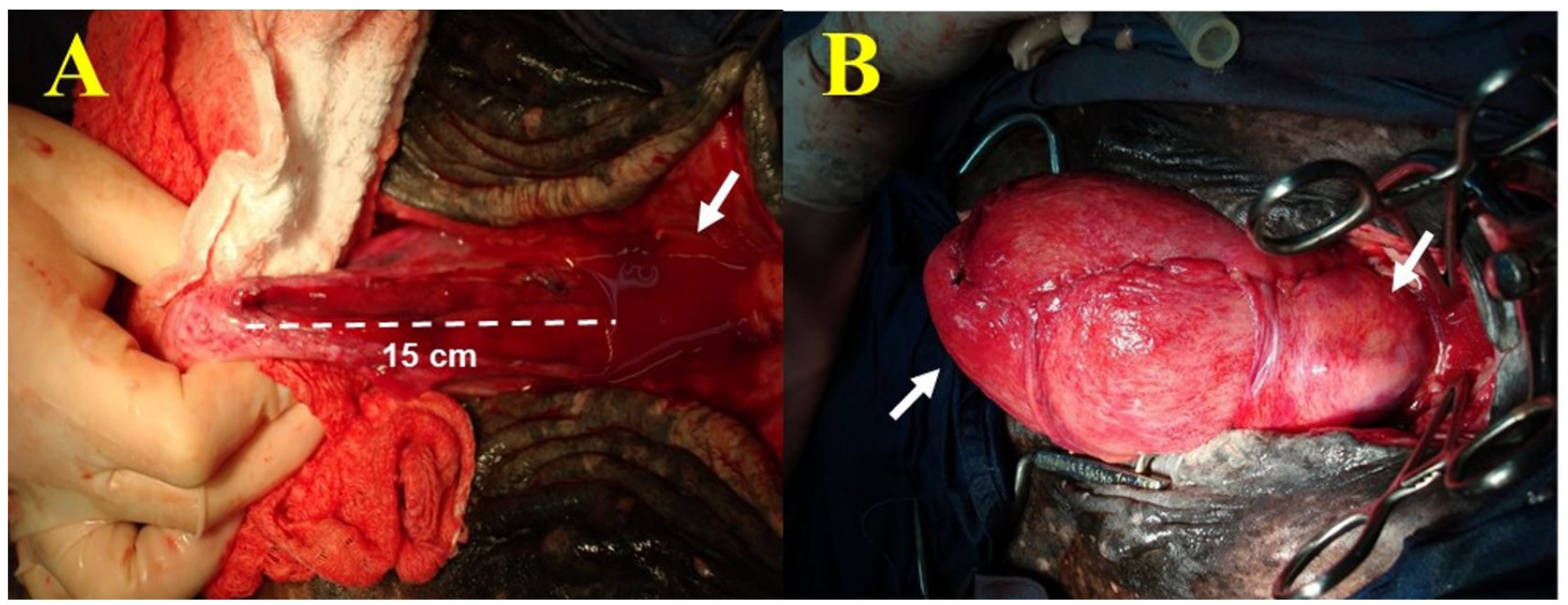

Figure 2 - Intraoperative of cystorrhaphy in Mare B: A) Rupture point (dotted line) and free liquid in abdominal cavity (arrow); B) Aspect of the urinary bladder wound after being sutured and filled with lactated Ringer's solution, with no presence of a drain point, and presence of hyperemic areas due to uroperitoneum (white arrows).

per rectum examination, a small colon eventration was evidenced through an incisional hernia of approximately $5 \mathrm{~cm}$. The urinary bladder was drained by catheterization, showing a more viscous and slightly darkened yellow urine. At the cystoscopy, the bladder healing was satisfactory and transcutaneous ultrasonography showed extra-peritoneal intestinal loops; thus, laparorraphy was indicated. Eighty days later, returning to the hospital, the local edema in ventral region of abdomen was significantly decreased and suture stitches were still present. Mare was submitted to surgery to reduce the incisional hernia and suture a polypropylene cloth in both sides of the incision using an Ethibond ${ }^{\circledR}$ no. 5 suture thread to make an interrupted simple pattern. The abdominal subcutaneous area was sutured using Prolene ${ }^{\circledR}$ no. 2 suture thread with simple continuous pattern and the skin with nylon no. 2-0 using simple interrupted pattern. The night after surgery, the hematoma in the left side of the hernia was drained, presenting a large amount of blood and coagulum. Until day 2 after surgery, the mare received intravenous enrofloxacin $5 \mathrm{mg} / \mathrm{kg}$ btw SID and flunixin meglumine $1.1 \mathrm{mg} / \mathrm{kg}$ btw SID, and the wound was cleaned using Dakin solution four times per day. At day 3 after surgery, she was submitted to laparotomy due to a suspicious small colon incarceration. However, several large adherences of small colon were evidenced within peritoneum and profuse bleeding, which were incompatible with life, so the mare was euthanized.

The mares' recovery may have been influenced by the gravity of each case, according to the position and extension of the wound in the urinary bladder. In animal B, a larger and more caudal abdominal incision was necessary compared to animal A to allow observation and suture of the wound, which was twice as long, increasing the risk of incisional hernia and eventration. Complementarily, the rupture point in animal $\mathrm{B}$ was located in the ventral region of the bladder, whereas, in animal A, the rupture occurred in the dorsal region. These findings probably influenced the larger amount of free liquid present in the abdominal cavity of animal B, because almost all produced urine was drained from the cavity by gravity. This explains the anuria observed in animal B since the day before the attendance, while animal A was still able to urinate. Thus, animal B's more serious uroperitoneum and sequenced abdominal surgeries favored formation of adherences. Besides these factors, washing mare A's abdominal cavity with lactated Ringer's solution and pouring lactated Ringer's solution with dimethyl sulfoxide and heparin may have impeded the formation of adherences during the postoperative period. This procedure is recommended by the literature to relieve distention and pressure in the cavity, as well as to decrease chemical irritation of serosal surfaces caused by urine (May et al., 2008).

Diagnostic methods used in each case were efficient and sufficient to determine the occurrence of urinary bladder rupture, confirmed during surgery, and its correction also occurred satisfactorily. While animal A's prognosis was good, in view of its general state, abdominal incision performed, position and extension of the wound, animal B's prognosis was poor due to a more severe uroperitoneum, longer abdominal incision and longer bladder wound. It is necessary to emphasize that the euthanasia of animal B was 
mainly due to complications on celiorraphy, conditions that lead to another operations and later visceral adherences.

In conclusion, even though urinary bladder rupture is very uncommon in adult mares free from the most common predisposal factors, they are still susceptible, and its occurrence can be properly assessed through simple diagnostic methods like ultrasonography and abdominocentesis. There are many elements that influence case severity and, therefore, the animal's recovery. Not only must factors directly related to cystorrhexis be taken in account, but also surgical access and intensity of visceral manipulation during operation, since uroperitoneum by itself favors occurrence of complications such as adherences.

\section{References}

Hendrickson DA, Lee M. Repair of the ruptured equine bladder. In: Reagle CA, editor. Advances in equine laparoscopy. Ames, IA: Wiley-Blackwell; 2012. p. 221-28.

Jenei TM. Bladder rupture in the mature horse: diagnostic techniques. Equine Vet Educ. 2012;24(10):517-9. http:// dx.doi.org/10.1111/j.2042-3292.2012.00399.x.

Lillich JD, Fischer AT, DeBowes RM. Bladder. In: Auer JA, Stick JA. Equine surgery. 3rd ed. St. Louis, MO: Saunders Elsevier; 2006. p. 877-87. http://dx.doi.org/10.1016/B141-600123-9/50073-5.

May KA, Kuebelbeck KL, Johnson CM. Urinary bladder rupture secondary to penile and preputial squamous cell carcinoma in a gelding. Equine Vet Educ. 2008;20(3):135-9. http://dx.doi.org/10.2746/095777308X282408.

Rijkenhuizen ABM, Van Loon TJAM, Boswinkel M. Laparoscopic repair of a ruptured bladder in an adult mare. Equine Vet Educ. 2008;20(4):183-9. http://dx.doi. org/10.2746/095777308X292137.

\section{Conflict of Interest}

None of the authors of this paper has a financial or personal relationship with other people or organizations that could inappropriately influence or bias the content of the paper.

\section{Ethics Statement}

Since this manuscript is a clinical case report, it was not necessary the approve of the animal ethics committee.

\section{Acknowledgements}

The authors do not have any acknowledgements in this paper.

Tuohy JL, Hendrickson DA, Hendrix SM, Bohanon TC. Standing laparoscopic repair of a ruptured urinary bladder in a mature draught horse. Equine Vet Educ. 2009;21(5):25761. http://dx.doi.org/10.2746/095777309X409884.

Walesby HA, Ragle CA, Booth LC. Laparoscopic repair of ruptured urinary bladder in a stallion. J Am Vet Med Assoc. 2002;221(12):1737-41. http://dx.doi.org/10.2460/ javma.2002.221.1736. PMid:12494972.

Financial Support: This paper had no financial support.

Authors Contributions: Carla Bargi Belli was responsible for the examination and clinical diagnosis of the cases. Luis Claudio Lopes Correia da Silva, Aline Magalhães Ambrósio and Paulo Ari Tietböhl Leiria were responsible for the surgery, anesthesia and postoperative monitoring of the animals. Carla Bargi Belli and Ronaldo Avella Lavado were responsible for article writing, with the final approval of the other authors. 